\title{
IZVOR STRESA U MEDICINSKIH SESTARA - PRIMALJA SVEUČILIŠNE KLINIČKE BOLNICE MOSTAR
}

\author{
Ljevak Ivona ${ }^{1}$, Romić Marko ${ }^{2}$, Vasilj Ivan ${ }^{1}$, Šimić Josip $^{1}$, Perić Olivera ${ }^{1}$ \\ ${ }^{1}$ Fakultet zdravstvenih studija, Sveučilište u Mostaru, 88000 Mostar, Bosna i Hercegovina \\ ${ }^{2}$ Centar za mentalno zdravlje, Dom zdravlja Mostar, 88000 Mostar, Bosna i Hercegovina \\ Rad je primljen 08.08. 2016. Rad je recenziran 19.09.2016. R R R Re prihvaćen 05.10.2016.
}

\section{SAŽETAK}

UVOD: U znanstvenu uporabu stres prvi puta ulazi u kontekstu fizikalnih znanosti u 17. stoljeću, dok se u 19. stoljeću na njega nailazi i u medicini, gdje se o stresu raspravlja kao o uzroku bolesti. Poznato je da brojni stresni čimbenici pridonose povećanom broju psihičkih smetnji i psihosomatskih bolesti kod medicinskih sestara.

CILJ: Procijeniti prisutnost i izvor stresa u medicinskih sestara/primalja Klinike za ginekologiju i porodništvo Sveučilišne kliničke bolnice Mostar.

METODE: Provedeno je anketno istraživanje (presječna studija) u Klinici za ginekologiju i porodništvo Sveučilišne kliničke bolnice Mostar gdje su se analizirali podaci 33 ispitanika na osnovu upitnika o stresorima na radnom mjestu bolničkih zdravstvenih djelatnika na osnovu 37 anketnih pitanja. Primijenjene su osnovne statističke metode srednje vrijednosti, t-test, deskriptivna statistika. Sve ispitanice su potpisale informirani pristanak.

REZULTATI: Istraživanje je pokazalo kako profesionalni i intelektualni zahtjevi, kao posebna kategorija izvora stresa nose najveću povezanost $s$ ukupnim doživljajem stresa. Najveća povezanost pojedinačnih kategorija stresa je između profesionalnih i intelektualnih zahtjeva, opasnosti i štetnosti na poslu. Izvori stresa u medicinskih sestara najviše su izraženi u kategoriji javnih kritika i sudske tužbe, smjenskoga rada te organizacije i financija, a najmanji su uzrok stresa u kategoriji sukoba i komunikacije.

ZAKLJUČAK: Izvori stresa u medicinskih sestara/primalja najizraženiji su u slučaju javnih kritika i sudske tužbe, smjenskoga rada, organizacije i financija. Profesionalni i intelektualni zahtjevi nose najveću povezanost s ukupnim doživljajem stresa. Najveća povezanost stresa je između profesionalnih i intelektualnih zahtjeva i opasnosti i štetnosti na poslu.

Ključne riječi: stres, primalje, rad, pacijenti, opasnost

\section{UVOD}

U znanstvenu uporabu stres prvi put ulazi u kontekstu fizikalnih znanosti u 17. stoljeću, dok se u 19. stoljeću na njega nailazi i u medicini, gdje se o stresu raspravlja kao o uzroku bolesti (1). Stanje stresa na poslu može se definirati kao niz, za pojedinca štetnih, fizioloških, psiholoških i bihevioralnih reakcija na situacije u kojima zahtjevi posla nisu u skladu s njegovim sposobnostima, mogućnostima i potrebama (2). Naglasak novijih konceptualizacija stresa je na interakciji osoba - okolina. Prema Ajduković profesionalni stres označava neusklađenost između zahtjeva radnog mjesta i okoline spram naših mogućnosti, želja i očekivanja da tim zahtjevima udovoljimo (3). Medicinske sestre, s posebnim osvrtom na primalje, imaju veliku odgovornost za zdravlje i živote, kako majki porodilja, tako i novorođenog djeteta. Izloženost specifičnim stresorima poput kemijskih, bioloških i fizikalnih, te smjenskom radu svrstava sestrinstvo u visoko stresne profesije. Produljeno radno vrijeme, smjenski i noćni rad, odgovornost pri donošenju odluka, složenost i dinamika radnih obveza, kontakt s trudnicama i njihovim obiteljima, rad s novorođenom djecom, emocionalno iscrpljivanje, te loša organizacija na radnom mjestu pridonose povećanom broju psihičkih smetnji i psihosomatskih bolesti u medicinskih sestara. Poznavanje izvora stresa i njegovih utjecaja na zdravlje i učinkovitost $u$ radu važno je za cijelu radnu organizaciju.

Cilj istraživanja je procijeniti prisutnost i izvor stresa na radnom mjestu $u$ medicinskih 
sestara-primalja Klinike za ginekologiju i porodništvo Sveučilišne kliničke bolnice Mostar.

\section{ISPITANICI I METODE}

Riječ je o presječnom istraživanju koje je provedeno od 27. travnja do 8. srpnja 2015. godine u Sveučilišnoj kliničkoj bolnici (SKB) Mostar. Ispitnu skupinu činile su 33 medicinske sestre-primalje iz Klinike za ginekologiju i porodništvo SKB Mostar. Provedeno istraživanje izvršeno je pomoću upitnika za doživljaj stresa na radnom mjestu koji je izrađen u Školi narodnog zdravlja „Andrija Štampar“, Medicinski fakultet Sveučilišta u Zagrebu, u sklopu projekta Ministarstva znanosti, obrazovanja i športa: Zdravlje na radu i zdravi okoliš, br. 19/16. Upitnik o stresorima na radnom mjestu bolničkih zdravstvenih djelatnika sadrži 37 pitanja (čestica) vezanih za doživljaj stresa na radu, koji su stupnjevani Likertovom ljestvicom raspona od 1 do 5. Upitnik se sastoji od 6 kategorija: a) Organizacija i financije (neadekvatna osobna primanja; neadekvatna materijalna sredstva za primjeren rad; neadekvatan radni prostor; mala mogućnost napredovanja; oskudna komunikacija s nadređenima; nedostatan broj djelatnika; loša organizacija posla; svakodnevne nepredviđene situacije; administrativni poslovi; preopterećenost poslom); b) Javna kritika i sudske tužbe (prijetnja sudske tužbe i/ili parničenje; neadekvatna očekivanja od strane bolesnika ili obitelji; izloženost neprimjerenoj javnoj kritici; pogrešno informiranje bolesnika od strane medija i drugih izvora; sukobi s bolesnikom ili članovima obitelji bolesnika; nemogućnost odvajanja profesionalnog i privatnog života; 24 -satna odgovornost); c) Opasnosti i štetnosti na poslu (strah od izloženosti ionizacijskom zračenju; strah od izloženosti inhalacijskim anesteticima; strah od izloženosti citostaticima; strah zbog mogućnosti zaraze; strah zbog mogućnosti ozljede oštrim predmetom; suočavanja s neizlječivim bolesnicima); d) Sukobi i komunikacija na poslu (sukobi s kolegama; sukobi s drugim suradnicima; oskudna komunikacija s kolegama; sukobi s nadređenima); e) Smjenski rad (noćni rad; smjenski rad; prekovremeni rad; dežurstva) i f) Profesionalni i intelektualni zahtjevi (uvođenje novih tehnologija; „bombardiranje“ novim informacijama iz struke; nedostatak odgovarajuće trajne edukacije; nedostupnost potrebne literature; pritisak vremenskih rokova za izvršenje zadataka; vremensko ograničenje za pregled pacijenta). Čestice upitnika su tvrdnje koje izražavaju stavove koji su evaluirani na ljestvici procjene od 1 - uopće se slažem do 5 - potpuno se slažem. Tvrdnje su jasne, kratke, nedvosmislene i bez više pojmova koje bi ispitanici mogli shvatiti kao objekt procjene. Ispitanici su na temelju ljestvice procjene iskazali stupanj slaganja/neslaganja sa svakom od tvrdnji. Rezultat ispitanika na ljestvici jednak je zbroju rezultata na pojedinim česticama (4). Ovaj upitnik je valjan i pouzdan mjerni instrument za procjenu stresa na radnom mjestu, te je na istom napravljena psihometrijska evaluacija kroz više istraživanja na temu stresa u zdravstvenih djelatnika. Korištene statističke metode u ovom istraživanju su T-test i Pearsonov koeficijent korelacije. $P$ vrijednost manja od 0,05 smatrala se statistički značajnom.

\section{REZULTATI}

Ukupan doživljaj stresa na radnom mjestu u medicinskih sestara-primalja može se ocijeniti kao umjeren (na skali od 1 do 100 on iznosi 51). Izvori stresa najviše su izraženi u kategorijama Javna kritika $i$ sudske tužbe, Smjenski rad i Organizacija i financije. Kategorija Sukobi i komunikacija na poslu izdvaja se kao najmanje stresna $(\mathrm{p}=0,003)$. (Slika 1$)$.

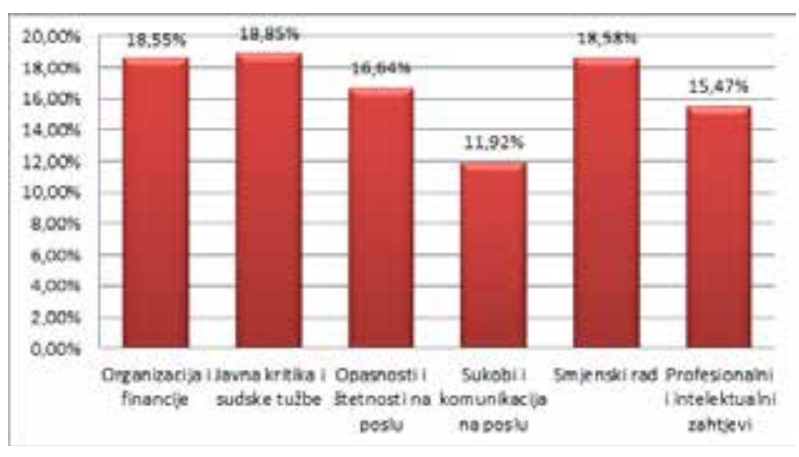

Slika 1. Ukupan doživljaj stresa u medicinskih sestara-primalja u SKB Mostar

U kategoriji Organizacija i financije kao najjači pojedinačni stresori izdvajaju se Neadekvatna osobna primanja i Preopterećenost poslom (Slika 2). 

Mostar. Zdravstveni glasnik. 2016;2: 65-71.

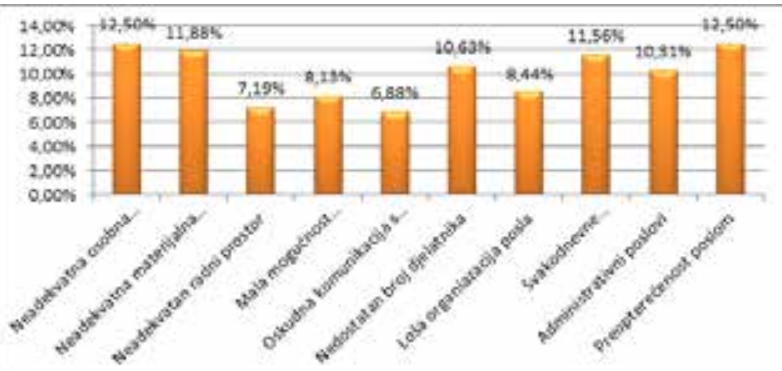

Slika 2. Organizacija i financije kao uzrok stresa

U kategoriji Javna kritika i sudske tužbe najveći uzročnici stresa su: 24-satna odgovornost, Izloženost neprimjerenoj javnoj kritici i Pogrešno informiranje bolesnika od strane medija i drugih izvora. Najmanji izvor stresa u ovoj kategoriji odnosi se na Sukobs bolesnikom ili članovima obitelji bolesnika (Slika 3).

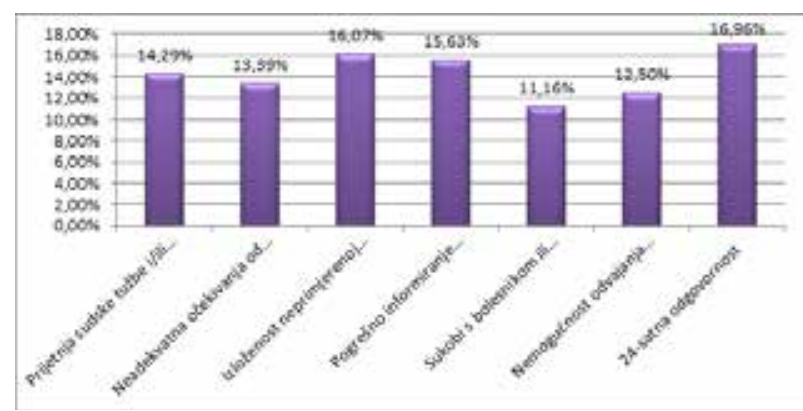

Slika 3. Javna kritika i sudske tužbe kao izvori stresa

Strah zbog mogućnosti zaraze najviše pridonosi stresu u kategoriji Opasnosti i štetnosti na poslu (Slika 4).

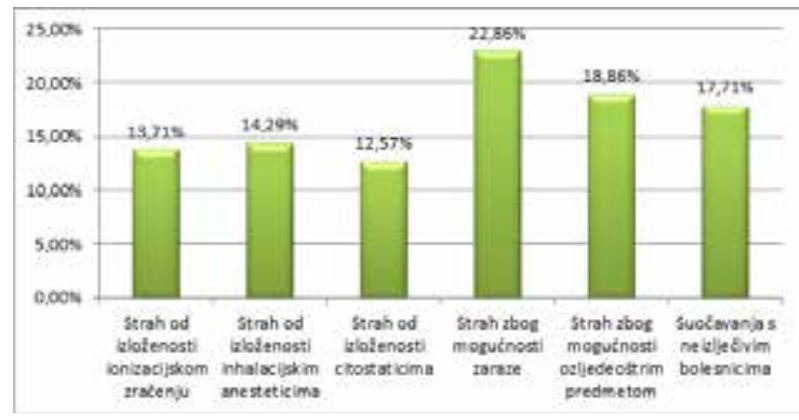

Slika 4. Opasnosti i štetnosti na poslu kao izvori stresa

Slika 5. prikazuje rezultate ispitanika u kategoriji Sukob i komunikacije s kolegama kao uzročnika stresa na radnome mjestu. Najveći strah u ispitanika izaziva sukob s kolegama, dok druge vrste sukoba u ovoj kategoriji stvaraju manji stres iako bez statističke značajnosti (Slika 5).

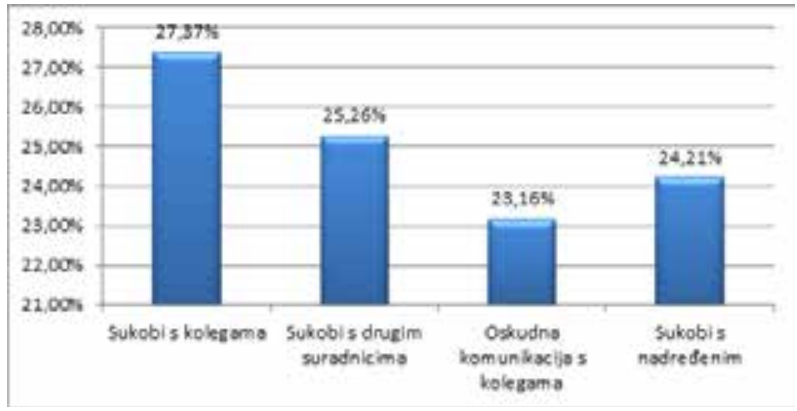

Slika 5. Sukob i komunikacija s kolegama kao uzrok stresa

Smjenski rad također utječe na stres zaposlenika, a potkategorija koja najviše pridonosi stresu je Noćni rad, zatim slijede Smjenski rad, Prekovremeni rad i Cjelodnevna dežurstva (Slika 6).

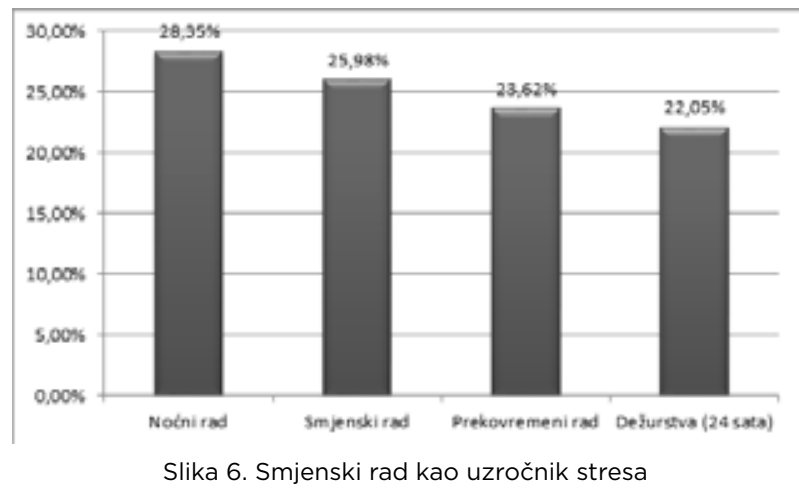

Posljednju kategoriju stresogenih čimbenika čine Profesionalni i intelektualni zahtjevi. Najveći izvor stresa u ovoj skupini čine podkategorije Pritisak vremenskih rokova za izvršenje zadataka i Vremensko ograničenje za pregled pacijenta. (Slika 7).

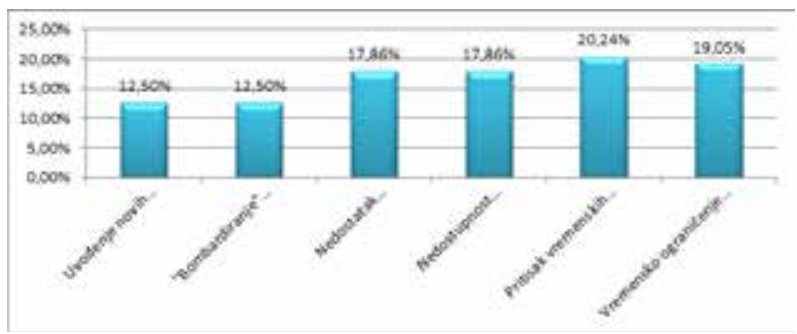

Slika 7. Profesionalni i intelektualni zahtjevi kao izvori stresa

Profesionalni i intelektualni zahtjevi, kao zasebna kategorija izvora stresa, imaju najveću povezanost $s$ ukupnim doživljajem stresa ( $\mathrm{p}=0,833)$. Najveća povezanost pojedinačnih kategorija stresa je između Profesionalnih i intelektualnih zahtjeva i Opasnosti $\mathrm{i}$ štetnosti na poslu $(\mathrm{p}=0,708)$ (Tablica 1$)$. 
Tablica 1. Korelacija pojedinih kategorija

\begin{tabular}{|c|c|c|c|c|c|c|c|}
\hline $\begin{array}{l}\text { Pearsonov } \\
\text { koeficijent } \\
\text { korelacije }\end{array}$ & $\begin{array}{l}\text { Ukupni } \\
\text { do- } \\
\text { življaj } \\
\text { stresa }\end{array}$ & $\begin{array}{l}\text { Organi- } \\
\text { zacija i } \\
\text { financije }\end{array}$ & $\begin{array}{l}\text { Javna } \\
\text { kritika i } \\
\text { sudske } \\
\text { tužbe }\end{array}$ & $\begin{array}{c}\text { Opd- } \\
\text { snost i } \\
\text { štetnost } \\
\text { na poslu }\end{array}$ & $\begin{array}{l}\text { Sukobi i } \\
\text { komuni- } \\
\text { kacija na } \\
\text { posilu }\end{array}$ & $\begin{array}{l}\text { Smjen- } \\
\text { ski rad }\end{array}$ & $\begin{array}{c}\text { Profesi- } \\
\text { onalni i } \\
\text { intelek- } \\
\text { tualni } \\
\text { zahtjevi }\end{array}$ \\
\hline $\begin{array}{l}\text { Ukupni } \\
\text { doživljaj stresa }\end{array}$ & 1,000 & ,711 & ,790 & ,773 & ,626 & ,499 & ,833 \\
\hline $\begin{array}{l}\text { Organizaciija i } \\
\text { financije }\end{array}$ & ,711 & 1,000 &, 431 & ,339 & ,404 & ,157 & ,495 \\
\hline $\begin{array}{l}\text { Javna kritika i } \\
\text { sudske tužbe }\end{array}$ & ,790 &, 431 & 1,000 & ,477 & ,504 &, 448 & ,528 \\
\hline $\begin{array}{l}\text { Opasnost i } \\
\text { štetnost na } \\
\text { poslu }\end{array}$ & ,773 & ,339 & ,477 & 1,000 &, 534 & ,253 & ,708 \\
\hline $\begin{array}{l}\text { Sukobi i } \\
\text { komunikacija } \\
\text { na poslu }\end{array}$ & ,626 & ,404 &, 504 &, 534 & 1,000 &,- 049 & ,388 \\
\hline Smjenski rad & ,499 & 157 & ,448 & ,253 &,- 049 & 1,000 & 397 \\
\hline $\begin{array}{l}\text { Profesionalni } \\
\text { i intelektualni } \\
\text { zahtjevi } \\
\end{array}$ & 833 & ,495 &, 528 & ,708 & ,388 & ,397 & 1,000 \\
\hline $\begin{array}{l}\text { Ukupni } \\
\text { doživljaj stresa }\end{array}$ & . & ,000 & ,000 & ,000 & ,000 & ,002 & ,000 \\
\hline $\begin{array}{l}\text { Organizacija i } \\
\text { financije }\end{array}$ & ,000 & . & ,006 & 027 & ,010 & ,192 & ,002 \\
\hline $\begin{array}{l}\text { Javna kritika i } \\
\text { sudske tužbe }\end{array}$ & ,000 & ,006 & . & ,003 &, 001 & ,004 & ,001 \\
\hline $\begin{array}{l}\text { Opasnost i } \\
\text { štetnost na } \\
\text { poslu }\end{array}$ & ,000 & 027 & ,003 & & ,001 & ,078 & ,000 \\
\hline $\begin{array}{l}\text { Sukobi i } \\
\text { komunikacija } \\
\text { na poslu }\end{array}$ & ,000 & ,010 &, 001 &, 001 & . & ,394 & ,013 \\
\hline Smjenski rad & ,002 & ,192 & ,004 & ,078 & ,394 & . & ,011 \\
\hline $\begin{array}{l}\text { Profesionalni } \\
\text { i intelektualni } \\
\text { zahtjevi }\end{array}$ & ,000 & ,002 & ,001 & ,000 & ,013 & ,011 & \\
\hline $\begin{array}{l}\text { Ukupni } \\
\text { doživljajaj stresa }\end{array}$ & 33 & 33 & 33 & 33 & 33 & 33 & 33 \\
\hline $\begin{array}{l}\text { Organizacija i } \\
\text { financije }\end{array}$ & 33 & 33 & 33 & 33 & 33 & 33 & 33 \\
\hline $\begin{array}{l}\text { Javna kritika i } \\
\text { sudske tužbe }\end{array}$ & 33 & 33 & 33 & 33 & 33 & 33 & 33 \\
\hline $\begin{array}{l}\text { Opasnost i } \\
\text { štetnost na } \\
\text { poslu }\end{array}$ & 33 & 33 & 33 & 33 & 33 & 33 & 33 \\
\hline $\begin{array}{l}\text { Sukobi i } \\
\text { komunikacija } \\
\text { na poslu }\end{array}$ & 33 & 33 & 33 & 33 & 33 & 33 & 33 \\
\hline Smjenski rad & 33 & 33 & 33 & 33 & 33 & 33 & 33 \\
\hline $\begin{array}{l}\text { Profesionalni } \\
\text { i intelektualni } \\
\text { zahtjevi } \\
\end{array}$ & 33 & 33 & 33 & 33 & 33 & 33 & 33 \\
\hline
\end{tabular}

\section{RASPRAVA}

Nastojanjem da se rasvijetli fenomen psihološkog stresa u radnoj okolini razvijen je čitav niz modela koji se razlikuju po svojoj složenosti. Detaljnijom analizom mogu se u pravilu klasificirati u dvije skupine (4). Jednu čine uži modeli koji stres definiraju kao rezultat neodgovarajućih zahtjeva radne okoline koji su u neskladu s mogućnostima zaposlenih. U drugu kategoriju spadaju modeli koji koriste širi pristup te promatraju stres u radu kao izraz opće neravnoteže između karakteristika radne situacije i individualnih osobina radnika. Jedan od prihvaćenih modela stresa je transakcijski model. Ključni predstavnici ovog modela su Lazarus i suradnici, a ubraja se u suvremene modele stresa koji podrazumijevaju uzajamni odnos između pojedinca i njegove okoline odnosno onoga što se objektivno događa (5). Znači, prema Lazarusu, na profesionalni stres utječu vanjski čimbenici, odnosno događaji koje osoba procjenjuje ugrožavajućima. Izvor stresa (stresor) može biti vanjski događaj ili niz događaja koje osoba procjenjuje ugrožavajućima, a stres je unutrašnje stanje ili doživljaj (6). Transakcijski model stresa posebno ističe značaj kognitivnih procesa $\mathrm{i}$ individualnih razlika $\mathrm{u}$ procjeni događaja $\mathrm{u}$ vanjskoj sredini kao i međuovisnost čimbenika okoline i osobe koja doživljava stres, te promjenjivost spomenutih čimbenika pod utjecajem transakcije. Sa stanovišta koje zastupa Lazarus, ono što je stresno za jednu osobu u određenom trenutku ne mora biti stresno za drugu osobu ili za istu osobu u nekom drugom trenutku. Ajduković D. pod stresorima navodi vanjske čimbenike, ali i one koji se odnose na specifičnosti pojedinca, te stresore dijeli na vanjske i unutarnje (8). Cooper i suradnici, primjenjujući transakcijski model na profesionalni stres, usmjerili su se na tri ključna elementa: 1) izvore profesionalnog stresa; 2) posljedice po pojedinca i organizaciju i 3) razlike u ličnosti i ponašanju (8).

U pojedinim zanimanjima pojavljuju se uz opće stresore; i specifični stresori karakteristični upravo za to zanimanje. Opći stresori uključuju: smjenski rad, lošu organizaciju, nemogućnost trajnog profesionalnog obrazovanja, premalo djelatnika, međuljudske sukobe i dr. specifični stresori, npr. 
za medicinare uključuju: neadekvatna materijalna sredstva za primjeren rad, mala mogućnost napredovanja, oskudna komunikacija s nadređenima, nedostatan broj djelatnika, loša organizacija posla, preopterećenost poslom, prijetnja sudske tužbe, izloženost neprimjerenoj javnoj kritici, nemogućnosti odvajanja profesionalnog i privatnog života, sukobi s kolegama, sukobi s nadređenima, noćni rad te smjenski rad. (9). Prema rezultatima našeg istaživanja najučestaliji izvor stresa u sestara primalja su stresori iz grupe Javnih kritika i sudske tužbe, Smjenskoga rada te Organizacije i financija. Slično istraživanje uradili su Ekić S, Primorac A i Vučić B pod nazivom "Profesionalni stres kod medicinskih sestara i tehničara". Odabirom rezultata specifičnih za rad medicinskih sestara od 25 stresora koji se mogu detektirati u profesiji, stresor neadekvatne plaće ocijenjen kao najstresniji (kao i u našem istraživanju u kategoriji "Organizacija i financije"), a komunikacija s osobama oštećena vida ili sluha kao najmanje stresna. Stresori koji se odnose na komunikaciju unutar tima nisko su ocijenjeni (isto kao u našem primjeru). Prekapacitiranost poslom te odgovornost za stručno i administrativno funkcioniranje odjela medicinske sestre i tehničari na rukovodećem mjestu ocijenili su najviše stresnim. Visoko je ocijenjen $i$ stresor „nedostatak vremena za bavljenje bolesnicima“, a stresor „osjećaj izoliranosti od kolegica i kolega vezano uz funkciju rukovodeće osobe“ prikazan je kao najmanje stresan (11).

Istraživanje pod nazivom "Stres uzrokovan radnim okruženjem medicinskih sestara/tehničara $u$ Općoj bolnici Dubrovnik" proveli su Marlais M i Hudorović N. Medicinske sestre i tehničari u bolnicama doživljavaju više različitih čimbenika kao stresore na radu s velikim intenzitetom. Među najčešćim stresorima kod ispitanika prepoznati su stresori iz skupine financijskih i organizacijskih čimbenika, baš kao što je slučaj i s našim istraživanjem (12).

Stresori mogu proizlaziti iz osobina radne okoline, organizacije rada i načina komuniciranja u organizaciji, osobina pojedinaca, kao i mnogih drugih svakodnevnih čimbenika koje je teško uvijek kvalificirati u određene kategorije jer su previše ovisni o čitavom sklopu odnosa u ukupnoj socijalnoj situaciji u kojoj se događaju.

\section{ZAKLJUČCI}

1. Izvori stresa $\mathrm{u}$ medicinskih sestara-primalja $\mathrm{u}$ Klinici za ginekologiju i porodništvo SKB Mostar najviše su izraženi u kategoriji Javnih kritika i sudske tužbe, Smjenskoga rada i Organizacije i financija, a najmanji je izvor stresa u kategoriji Sukob i komunikacije.

2. Istraživanje je pokazalo kako Profesionalni i intelektualni zahtjevi, kao posebna kategorija izvora stresa, nosi najveću povezanost s ukupnim doživljajem stresa. Najveća povezanost pojedinačnih kategorija stresa je između Profesionalnih i intelektualnih zahtjeva i Opasnosti i štetnosti na poslu.

\section{LITERATURA}

1. Lazarus RS, Folkmann S. Stres, procjena i suočavanje, Naklada Slap: Jastrebarsko; 2004.

2. Sauter S, Murphy L. Stress at work, NIOSH Publication No. 99-101, Cincinnati: NIOSH, Cincinnati, 1999.

3. Ajduković D, Ajduković, M. (ur.). Zašto je ugroženo mentalno zdravlje pomagača? Pomoć i samopomoć u skrbi za mentalno zdravlje pomagača. Zagreb: Društvo za psihološku pomoć; 1996.

4. Milošević M. Izrada mjernog instrumenta stresa na radnom mjestu bolničkih zdravstvenih djelatnika i procjena njegove uporabne vrijednosti. Sveučilište u Zagrebu: Medicinski fakultet; 2010.

5. Šverko B. Važnost rada u životu pojedinca i prilog evaluaciji jednog kognitivnog modela. Psihologija; 1984;17(3):48-60.

6. Arambašić L. Stres i suočavanje - teorijski modeli i njihove implikacije za problem nezaposlenosti. Suvremena psihologija; 2003;6:103-127

7. Lazarus RS, Folkman S. Stress, appraisal and coping, New York: SpringerPublishingComp; 1984.

8. Ajduković D. Izvori profesionalnog stresa i sagorijevanja pomagača. U: Ajduković D, Ajduković M. (ur.), Pomoć i samopomoć u skrbi za mentalno zdravlje pomagača. Zagreb: Društvo za psihološku pomoć; 1996. str. 29-37. 
9. Cooper CL, Sloan SJ, Williams S. Occupational stress indicator. management guide. Windsor; NFER-Nelson; 1988.

10. Pavičević L, Bobić J. Stres na radu. U: Šarić M, Žuškin E, sur. Medicina rada i okoliša. Zagreb: Medicinska naklada; 2002. str. 530-37.
11.Ekić S, Primorac A, Vučić B. Profesionalni stres kod medicinskih sestara i tehničara. JAHS, 2016;2(1):39-46.

12. Marlais M, Hudorović N. Stres uzrokovan radnim okruženjem medicinskih sestara/tehničara u Općoj bolnici Dubrovnik. SG/NJ 2015:20;72-14. 


\title{
SOURCE OF STRESS IN NURSES AND MIDWIVES AT THE UNIVERSITY CLINICAL HOSPITAL IN MOSTAR
}

\author{
Ljevak Ivona ${ }^{1}$, Romić Marko ${ }^{2}$, Vasilj Ivan ${ }^{1}$, Šimić Josip $^{1}$, Perić Olivera ${ }^{1}$ \\ ${ }^{1}$ Faculty of Health Studies, University of Mostar, 88000 Mostar, Bosnia and Herzegovina \\ ${ }^{2}$ Mental Health Center, Medical Center Mostar, 88000 Mostar, Bosnia and Herzegovina
}

\begin{abstract}
INTRODUCTION: The scientific use of stress first enters the context of physical sciences in the $17^{\text {th }}$ century, while in the $19^{\text {th }}$ century it is used in medicine, where it is discussed as one of the causes of disease. It is known that a number of stress factors contribute to the increased number of mental disorders and psychosomatic diseases in nurses.

OBJECTIVE: Assess the presence and source of stress in nurses and midwives at the Department of Obstetrics and Gynecology, at the University Clinical Hospital in Mostar.

METHODS: We carried out a research (cross-sectional study) at the Department of Obstetrics and Gynecology, University Clinical Hospital Mostar, where we analyzed the data from 33 respondents, based on their answers from a questionnaire about stress on the workplace; the questionnaire consisted of 37 questions. We used basic statistical methods, median value, t-test, and descriptive statistics. All respondents signed an informative consent.

RESULTS: The research showed that professional and intellectual requirements, as a special category of source of stress have the greatest correlation with the overall experience of stress. The largest connection of single categories of stress is between professional and intellectual requirements, risks and hazards at work. Sources of stress in nurses are most evident in the category of public criticism and lawsuits, shift work, organization and finance, while they are the lowest in the category of conflict and communication.

CONCLUSION: The sources of stress in nurses - midwives are most evident in the case of public criticism and lawsuits, shift work, organization and finance. Professional and intellectual requirements bare the greatest correlation with the overall experience of stress. The largest correlation of stress is between professional and intellectual demands and risks and hazards at work.
\end{abstract}

Key words: stress, midwives, work, patients, hazard

Correspondence:

Ivona Ljevak

Email: ivonaljevak@gmail.com 